\title{
A Cognitive Sketch of the Lexical Item Phobia
}

\section{Azad Hasan Fatah}

Department of English, College of Languages, University of Sulaimani, Kurdistan Region, Iraq Email: azad.fatah@univsul.edu.iq

\section{Abstract}

This study is about the mode of representing lexical information in the mental lexicon. It carries out the investigation within the framework of Cognitive Lexical Semantics, a subfield of semantics which deals with the cognitive aspects of lexical meanings: what lexical items mean and how they are stored in the speaker's mind. It tries to substantiate two of its assumptions. One is that lexical items are polysemous by nature, i.e. having multiple senses. The other is that lexical items form categories of interrelated senses. Applying these tenets to the linguistic expression -phobia, I make two arguments. One is that it exhibits polysemy, having numerous senses. The other is that it forms a category, a network of interrelated senses. The central sense is called the prototype. The other senses which extend from the prototype are called the periphery. The theoretical aim is to show that the multiple senses of a lexical item are stored in the mind as a network. The descriptive aim is to portray the full semantic range of the lexical item phobia in English.

Keywords: category, network, polysemy, prototype, periphery.

\section{Introduction}

One pervasive property of language concerns polysemy, the natural phenomenon when a single lexical item has multiple related senses. A lexical item with more than one related sense is termed a polyseme. Take, for example, the lexical item paper. A close look at dictionaries on English language such as Longman Dictionary of Contemporary English (2003), Oxford Advanced Learner's Dictionary (2005) and Cambridge Advanced Learner's Dictionary (2013) shows that the lexical item paper has multiple senses. In The package was wrapped in brown paper, it refers to material. In The photo was on the front page of all the papers, it refers to newspapers. In Mr Jones thought my history paper was terrific, it refers to an article. In He never goes out without identification papers, it refers to documents. In She spent the evening marking Geography papers, it refers to exam sheets. The examples prove that in each sentence the lexical item paper 
has a different meaning. The examples confirm the basic principle that accounts for the existence of several closely related meanings in a single linguistic expression.

In a similar vein, the suffix -phobia has a handful of senses, as shown by the examples below:

zoophobia

xenophobia

nalgophobia

In the examples cited above, the suffix -phobia exhibits different senses. In zoophobia, it means fear of animals. In xenophobia, it means hatred of foreigners. In nalgophobia, it means intolerance of pain. The examples do not constitute an arbitrary collection, but form an interrelated string. The examples demonstrate the phenomenon of polysemy, whereby a lexical item exhibits multiple distinct yet related meanings. Concerning this phenomenon, two questions are posed. The first is: does a lexical item exhibit multiple senses, and if so, on what basis are its senses organised? The second is: are the senses related, and if so, what principles govern their interrelationship? The primary aim of the study is to find answers to such questions, show how lexical items behave in natural language, and describe how their semantic structures are organised. The secondary aim is to present a thorough description of the suffix -phobia, by identifying the different senses it exhibits and providing a different definition for each sense.

To answer the questions above, the study employs an approach called Cognitive Lexical Semantics. The new approach has to address two linguistic phenomena. One pertains to polysemy, whereby a lexical item has multiple related senses. The meaning of a lexical item displays flexibility. Through the creativity of the language user, it can be extended to cover new realms of experience, thus resulting in new senses. The other relates to category, whereby the multiple senses of a lexical item form a network. The senses gather around a nucleus, from which the extended ones are derived. The senses are organised in terms of distance from the nucleus, based on the degree of similarity. The more similar in meaning a sense is to the nucleus, the closer it is in distance. The new approach is chosen because it is adept at handling intricacies of linguistic data. It provides linguists with the necessary tools to plausibly account for the semantics of linguistic expressions, and eventually arrive at convincing results.

Before introducing the details of the new approach, let us first see how such questions are addressed by the previous endeavours in language study. 


\section{Previous endeavours}

To get a clear picture of the topic, I shall first briefly review the literature. First, I classify the literature into two types of endeavour, dealing with each in turn. Section 2.1 is a discussion of lexical endeavours embedded within formal linguistics. Section 2.2 is a review of lexicographical endeavours as demonstrated by dictionaries. Second, I single out the endeavours that are the most prominent on the topic, and examine the central claim of each endeavour. Third, I assess each type of endeavour with reference to the two lexical phenomena: polysemy and category. The purpose of the review is not to criticise any of the endeavours, but to see what they can bring to the current analysis.

\subsection{Formalist endeavours}

In Formal Lexical Semantics, descriptions of lexical meaning are built on two theories. One relates to homonymy, whereby the different meanings associated with a lexical item are unrelated to one another. As Cruse (2006: 133) explains, the unrelated senses are accidentally associated with the same linguistic form, and so treated as separate words. On the basis of this, the meanings associated with the suffix -phobia are unrelated although they share the same form. The other theory relates to monosemy, whereby a lexical item has a single relatively abstract meaning from which other senses are derived. In Ruhl's (1989) theory, the different meanings associated with a form are derived from it by context. In Pustejovsky's (1995) theory, the different meanings are derived by the application of a series of generative devices from an abstract representation. As appraised by Evans (2003: 89), these theories are not helpful for lexical analysis for two reasons. First, the meanings of a lexical item are not always context-dependent. Second, the meanings derived from an abstract representation are not justified.

In Formal Lexical Semantics, the multiple senses of a lexical item form a category based, as summarised by Taylor (1989: 23-24), on four assumptions. First, a category is defined in terms of a conjunction of necessary and sufficient features. The features are singly necessary and jointly sufficient for an entity to be a member of a category. Second, if an entity has all of the features, the entity is included in the category. If the entity does not have one or more of the features, the entity is excluded from the category. Third, the boundaries of a category are clearly defined. So, membership in a category is clear-cut. Fourth, the members of a category have equal status. There are no members which are better than others. This position is taken by Katz (1972), who lists many senses for a lexical item as long as they meet the necessary and sufficient features. In the mental lexicon, the different senses are represented as separate entries. On the basis of this, the multiple senses of the suffix -phobia cannot be included in one category 
because some of them do not share the same features, and are consequently unequal in status.

\subsection{Lexicographical endeavours}

When one scans dictionaries, e.g. Longman Dictionary of Contemporary English (2003), Oxford Advanced Learner's Dictionary (2005) and Cambridge Advanced Learner's Dictionary (2013), to see how the expression '-phobia' is treated, one finds that they display considerable deficiencies.

Firstly, dictionaries give only a very sketchy account of the expression under investigation.

They make no apparent contribution to the multiple readings of the expression. They miss drawing a fully-articulated account for the expression. This becomes evident when they fail to show that the expression exhibits polysemy, having numerous senses. The suffix -phobia, encodes different senses relative to the semantics of the root. In astraphobia, it means fear of thunder. In transphobia, it means hatred of transgender people. In acousticophobia, it means intolerance of noise. Without providing such notes, the language user would not be able to see the exact behaviour of the expression.

Secondly, dictionaries make no reference to alternative senses that relate to the expression.

They neglect the fact that the expression forms a category, a network of interrelated senses. This becomes evident when they fail to show that the suffix -phobia encodes distinct but related senses. The word cynophobia means both fear as well as intolerance of dogs. In such cases, the interpretation of the word is ambiguous. It is difficult to decide which of the two meanings is meant, Is s/he afraid or intolerant of dogs? Without providing such notes, the language user would not be able to relate the alternative senses that exist in the language.

Thirdly, dictionaries fail to give cross references to the antonymic counterparts of the expression. They do not take into account the roles of the alternative suffixes in triggering differences in the meanings of the alternative derivatives. This becomes evident when they fail to show that the difference in meaning between the two derivatives is due to the distinctive roles which the suffixes play in the language. Compare hydrophobia and hydrophilia. In hydrophobia, the suffix -phobia means dislike of water. In hydrophilia, the suffix -philia means love of water. Without such notes, the language user would not be able to choose the appropriate word in discourse. 


\section{Cognitive Lexical Semantics}

In Cognitive Lexical Semantics, descriptions of lexical meaning are built on the polysemy theory, whereby a lexical item has multiple related senses. Polysemy is considered a cognitive-social phenomenon, and so accorded utmost importance. Polysemy patterns, as Evans (2006: 329) states, reflect how lexical items are organised and structured in the mind. The meaning of a linguistic expression is dynamic and flexible, namely it is able to change to suit new experiences which language users encounter in life. As explained in Hamawand (2016: 71), this has to do with creativity, which is shown in two ways. One is the ability to create new forms to express new ideas. The other is the ability to extend the existing forms to encompass new meanings. The semantic structure of any linguistic expression is thus not rigid; it takes on new meanings and is continuously extending. A telling example is the polysemous expression by. In a house by the river, it means near. In a play by Shakespeare, it identifies person. In travelling by car, it indicates method. In paying by cheque, it describes manner. In getting worse by the minute, it states rate. In fifteen feet by twenty feet, it shows measurement ${ }^{1}$.

In Cognitive Lexical Semantics, a lexical item forms, due to polysemy, a category of interrelated senses. Grouping the multiple senses in a category is referred to as categorization. The category is structured in terms of prototype and periphery. The prototype is the conceptual centre. It is the most representative sense or the most salient instance of the category. The periphery includes the extended senses which are derived from the prototype via semantic extensions. The senses are extended by cognitive principles such as metaphor, metonymy, generalisation, specification and image schema transformations. The senses do not have to conform rigidly to the prototype. Some of the properties of the prototype may appear to be optional at the periphery. A good example is offered by the chair category. This category has properties like: a seat, a back and four legs. A kitchen chair is regarded as the prototype because it possesses almost all of the properties, whereas rocking chair, swivel chair, armchair, wheelchair and highchair are regarded as the periphery because they possess only some of the properties ${ }^{2}$.

To describe the polysemy of lexical items, Cognitive Lexical Semantics employs the general theory of category, based on the following assumptions.

1 - Categories are not defined by a set of necessary features which members of a category are expected to manifest. Some of the necessary features of the prototype may appear to be optional at the periphery. 
2. Categories display different degrees of salience. Members of a category have different status. The members which are salient are considered better exemplars and more important than those which are less salient.

3 Category boundaries are vague rather than clear. A category contains peripheral senses that do not conform rigidly to the prototype. Accordingly, all senses of a lexical item are included in the category.

4-Category membership is defined by similarity rather than identity. Category membership is not a question of either-or, but a matter of degree. Therefore, not every member is equally representative of a category.

4. The analysis

The lexical item phobia is a Greek word, taken from phobos, meaning 'irrational fear'.

According to Longman Dictionary of Contemporary English (2003), Oxford Advanced Learner's Dictionary (2005) and Cambridge Advanced Learner's Dictionary (2013), the lexical item phobia is a noun and means a permanent strong unreasonable fear of something, especially one that cannot be reasonably explained. It means a persistent fear, usually illogical and unreasonable, of an object, activity or situation. The phobia leads to a strong desire to avoid the thing feared despite the awareness that it is not dangerous. Examples illustrating this meaning are I had a phobia about going to the dentist, She has a phobia about snakes, He has a phobia about flying, and It took her a long time to overcome her bridge phobia. From the noun phobia, three suffixes can be derived. They are -phobe, -phobic and -phobia. Each suffix forms a different class of word, has its own meaning, and conveys a different mission in the language.

The suffix -phobe is used to form personal nouns, referring to someone who has a fear or dislike of what is named in the root. In a cynophobe, the suffix refers to a person who is afraid of dogs. In a neophobe, the suffix -phobe refers to a person who despises new or novel things. In a tobaccophobe, the suffix -phobe refers to a person who is intolerant of tobacco. In this sense, the suffix -phobe is antonymic to the suffix -phile, which denotes someone who has a fondness for or is interested in what is named in the root. In a Francophile, the suffix -phile refers to a person who loves France or the French culture and people. The difference in meaning between the two suffixes becomes clear by comparing the pair technophobe and technophile. In a technophobe, the suffix -phobe refers to a person who despises modern technology. In a technophile, the suffix -phile refers to a person who is interested in modern technology. 
The suffix -phobic is used in nouns to denote someone who has an illogical fear of what is stated in the root. In a claustrophobic, the suffix -phobic refers to a person who fears small enclosed places. In adjectives, the suffix -phobic means suffering from or having an exaggerated fear of something. In agoraphobic, the suffix describes a person as being afraid of crowds and open places. In this sense, the suffix -phobic is antonymic to the suffix -philic (variant of philous), which means having an affinity for or an inclination towards something. In Acidophilic, the suffix -philic describes something as preferring a relatively acid environment. The difference in meaning between the two suffixes becomes evident by comparing the pair Anglophobic and Anglophilic. In Anglophobic, the suffix -phobic means characterised by hatred of England and English things. In Anglophilic, the suffix -philic means characterised by admiration of England and English things.

The suffix -phobia indicates a strong unreasonable fear or hatred of the thing labelled in the root. In xenophobia, the suffix -phobia means hatred of foreigners. In this sense, it is antonymic to the suffix -philia, which indicates an abnormal love for or tendency towards a given thing. In Francophilia, the suffix -philia means love of French people and things. The difference in meaning between the two suffixes becomes obvious by comparing the pair Melophobia and Melophilia. In melophobia, the suffix -phobia means dislike of music. In melophilia, the suffix -philia means love of music. The suffix -phobia is the most productive type of phobos. It can combine with many words and express different senses. In this study, I propose three distinct senses for -phobia: the fear sense, the hatred sense and the intolerance sense. Each sense is the result of the interaction between the meanings of the root and the suffix. With regard to the examples, some are clear cases of the senses, whereas others are borderline cases. Whether the examples belong to one sense or another is a matter of degree. The examples, however, are numerous enough to reflect the complexity of the category of the suffix -phobia.

In this analysis, the establishment of the senses of -phobia and their classification into distinct (sub)types is dependent on two types of properties: internal and external. One internal property concerns the morphological nature of the root: whether it is concrete or abstract. The presence of each characteristic gives rise to a different meaning. Another internal property relates to the semantic nature of the root: whether it is psychological, sociological or physical. The presence of each characteristic brings about a different meaning. The external property involves the role of the speaker in shaping the language relative to communicative needs. The data used in the analysis are taken from different sources. One is the list of examples offered in Oxford Dictionary of Synonyms and 
Antonyms (2007: 511-2). The other is the list of examples offered online. In order to guarantee objectivity, the occurrences of the suffix were checked in the British National Corpus. Many of the words are of Greek origin, as shown by the use of the connecting vowel letter $o$. Yet, many words in English were coined in the late 19th and 20th century, with the introduction of psychotherapy and psychiatry.

Importantly, in many cases a number of the listed senses can occur in the same word. This is due to the polysemy of both the suffix and the root. In the word acrophobia, for instance, the sense of intolerance may go hand in hand with the sense of fear. Acrophobia is fear of heights, but at same time it is intolerance of heights. Aviophobia is a physical disposition to feel sick when flying as well as fear of flying. The sense of hatred may also go hand in hand with the sense of fear. In the word xenophobia, for instance, one meaning is that of hatred (psychological aversion) of strangers, whereas the other is that of fear of strangers, a predisposition to strangers as a threat. In such cases, the interpretation of the word is ambiguous. If you call someone xenophobic, which of the two meanings is meant? Are you afraid of a stranger or hateful of him or her on racist grounds?

\subsection{The fear sense}

The prototypical sense of the suffix -phobia describes an exaggerated, usually inexplicable and illogical, fear of something. Fear is fundamental to human experience. Fear refers to a psychological reaction which a person experiences as a result of encountering something perceived as a danger. A person suffering from a phobia tries to avoid the thing s/he fears. The fear sense arises when the suffix -phobia is attached to a root denoting a concrete entity. The background knowledge associated with the root and the suffix interacts to produce the overall meaning of the formation. Within the fear sense, two subtypes exist: general and specific. The general fear is considered to be the central sense. The specific fear is an extension of the general fear. Within each subtype, there arise minimal variations relative to the source of the fear. However, the variations do not change the central meaning of the suffix. In network connections, the nature of the combined elements provides different dimensions of motivation for semantic variations.

\subsubsection{General fear}

A general fear involves an extreme or irrational fear of a general class of entities. A general fear is usually connected to something general. The general fear subsumes different variants. In some formations, the suffix -phobia is attached to roots applying to animate entities to form nouns. A collection of formations which embodies fear of 
animate entities includes the following examples. Anthropophobia is fear of people. Zoophobia is fear of animals. Ornithophobia is fear of birds. Entomophobia is fear of insects. Botanophobia is fear of plants. Anthophobia is fear of flowers. In other formations, the suffix -phobia is attached to roots applying to inanimate entities to form nouns. A collection of formations which embodies fear of inanimate entities includes the following examples. Bibliophobia is fear of books. Hoplophobia is fear of weapons. Gephyrophobia is fear of bridges. Mechanophobia is fear of machines. Metallophobia is fear of metals. Chromophobia is fear of colours. What the afore-mentioned examples have in common is the concept of general fear of a concrete entity. They differ only in the source of the fear, ranging from animate to inanimate entities.

\subsubsection{Specific fear}

A specific fear involves an extreme or abnormal fear of a specific class of entities. A specific fear is usually connected to something specific. The fear is triggered by the presence of or exposure to a specific class of entities. As a result, the affected person tends to actively avoid direct contact with the class of entities. The specific fear is an extension of the general fear. The examples present a transposition of fear from general to specific. This case subsumes different variants.

In some formations, the suffix -phobia is attached to roots applying to animate entities to form nouns. A constellation of formations referring to people includes the following examples. Ochlophobia is fear of mobs. Androphobia is fear of men. Gynophobia is fear of women. Coulrophobia is fear of clowns. Demophobia is fear of crowds. Paedophobia is fear of children. Harpaxophobia is fear of robbers. Dentophobia is fear of dentists. A constellation of formations referring to animals includes the following examples. Arachnophobia is fear of spiders. Ophidiophobia is fear of snakes. Ailurophobia is fear of cats. Cynophobia is fear of dogs. Hippophobia is fear of horses. Musophobia is fear of mice. Apiphobia is fear of bees.

In other formations, the suffix -phobia is attached to roots applying to inanimate entities to form nouns. A representative list of formations referring to objects includes the following examples. Enetophobia is fear of pins. Belonephobia is fear of needles. Cyberphobia is fear of computers. Aurophobia is fear of gold. Doraphobia is fear of fur. Pteronophobia is fear of feathers. Pyrophobia is fear of fire. Spectrophobia is fear of mirrors. Robophobia is fear of robots. A representative list of formations referring to places includes the following examples. Batophobia is fear of high buildings. Hypsophobia is fear of high places. Claustrophobia is fear of being in small confined places. Scolionophobia is fear of schools. Agoraphobia is fear of public places. Nosocomephobia is fear of hospitals. Astrophobia is fear of outer space. A 
representative list of formations referring to natural environment includes the following examples. Hydrophobia is fear of water. Chionophobia is fear of snow. Cryophobia is fear of ice. Brontophobia is fear of thunder. Antlophobia is fear of floods. Limnophobia is fear of lakes. Nephophobia is fear of clouds. Pontamophobia is fear of rivers. Nebulaphobia is fear of fog.

\subsection{The hatred sense}

One step removed from the prototype is the hatred sense, in which the root still denotes a concrete entity, but the meaning is noticeably different. The suffix -phobia describes an unreasonable dislike of people or aversion to things. Hatred refers to an emotional attitude which an individual develops against particular people or things. This sense is linked to the fear sense. The fear sense deals with psychology, whereas the hatred sense deals with sociology and physiology. In the fear sense, the person is in the grip of psychological phobias, while in the hatred sense the person is in the throes of social and physiological phobias. The meaning of hatred stems from the meaning of fear; naturally one hates something one fears. Hence, -phobia is associated with hatred. Within the hatred sense, two subtypes exist: dislike and aversion. The aversion sense is an extension of the dislike sense. The dislike sense is social in nature, being caused by people. By contrast, the aversion sense is physiological in nature, being caused by things. Within each subtype, some variations relative to the cause come about, but they do not have any impact on the meaning of the suffix. In network connections, there exist multiple dimensions of motivation for new formations.

\subsubsection{Dislike of people}

This case is based on prejudice, a strong dislike of people who are different in some way. It is a social reaction against people which is unfair and unreasonable. The derived words denote a particular anti-ethnic or anti-demographic sentiment. A collection of formations denoting people includes the following examples. Americophobia is dislike of American people. Anglophobia is dislike of English people. Francophobia is dislike of French people. Sinophobia is dislike of Chinese people. Germanophobia is dislike of German people. Italophobia is dislike of Italian people. Scotophobia is dislike of Scottish people. Russophobia is dislike of Russian people. Polonophobia is dislike of Polish people. Turcophobia is dislike of Turkish people. A collection of formations denoting types of people includes the following examples. Homophobia is dislike of homosexuals. Lesbophobia is dislike of lesbians. Xenophobia is dislike of foreigners. Islamophobia is dislike of Muslims. Christianophobia is dislike of Christians. 
In this sense, the suffix -phobia can be compared with the prefix anti-. The two affixes, I argue, have different missions to carry out in language. The suffix -phobia means 'hating a particular thing or person'. In Americanophobia, the suffix -phobia means a strong dislike of Americans. The feeling of hatred towards others is often rooted in social behaviour. By contrast, the prefix anti- means 'opposed to or against a particular thing or person'. In Anti-American, the prefix anti- means opposed to or against America and its policies. The opposition stems from the psychology of people, the way the mind influences behaviour.

\subsubsection{Aversion to things}

This case is based on revulsion, a strong dislike of things. It is a physiological reaction which an individual forms against a stimulus. The derived words denote a feeling of repugnance towards something with a desire to avoid or turn from it. A sample list of formations includes the following examples. Osmophobia is aversion to smells. Phonophobia is aversion to sounds. Photophobia is aversion to light. Haemophobia is aversion to blood. Koniophobia is aversion to dust. Mysophobia is aversion to dirt. Cheimaphobia is aversion to cold. Thermophobia is aversion to heat. Anemophobia is aversion to wind. Heliophobia is aversion to sun. A sample list of formations referring to colours includes the following examples. Melanophobia is aversion to black. Porphyrophobia is aversion to purple. Xanthophobia is aversion to yellow. Chlorophobia is aversion to green. Chrysophobia is aversion to orange. Leukophobia is aversion to white.

\subsection{The intolerance sense}

Further from the prototype is the peripheral sense of intolerance, in which the root denotes an abstract entity. This transfer from a concrete perception to abstract interpretation is achieved by means of the cognitive mechanism of metaphor. In the cognitive model, abstract language is treated as a case of semantic extension, and figurative language is viewed as an integral part of linguistic organisation. The meaning of the suffix -phobia transfers from the original fear sense to the abstract intolerance sense. That is, the intolerance sense is an extension, through metaphor, of the fear sense. The fear sense concerns psychological aspects, whereas the intolerance sense concerns physical aspects. Intolerance refers to the indisposition to endure something or the sensitivity shown to certain kinds of things. Within the intolerance sense, two subtypes exist: tense actions and stressful situations. The intolerance sense of situations is an extension of the intolerance sense of actions. Within each subtype, some variations stem from the type of the source, but they in no way influence the meaning of the suffix. The 
point is that in network connections semantic modulation is the outcome of different dimensions of motivation.

\subsubsection{Intolerance of tense actions}

This case is based on unwillingness to do some actions. The derived words exhibit intolerance of physical actions. A cluster of formations includes the following examples. Aerophobia is intolerant of travelling by air. Hodophobia is intolerance of travelling. Aviophobia is intolerance of flying. Climacophobia is intolerance of climbing. Glossophobia is intolerance of speaking in public. Taxophobia is intolerance of paying taxes. Agyrophobia is intolerance of crossing the street. Ablutophobia is intolerance of bathing, washing, or cleaning. Motorphobia is intolerance of riding in a car. Phagophobia is intolerance of swallowing. Mastigophobia is intolerance of beating. Haptophobia is intolerance of touching. Kleptophobia is intolerance of stealing. Emetophobia is intolerance of vomiting. As the examples show, the use of metaphor serves to supply a tangible conceptual structure for the abstract concept. That is, there is a shift from concrete to abstract areas of experience.

\subsubsection{Intolerance of stressful situations}

This case is based on unwillingness to endure things. The derived words display intolerance of unpleasant situations. A cluster of formations includes the following examples. Autophobia is intolerance of loneliness. Eremophobia is intolerance of solitude. Scotophobia is intolerance of darkness. Peniaphobia is intolerance of poverty. Hypegiaphobia is intolerance of responsibility. Maniphobia is intolerance of insanity. Atelophobia is intolerance of imperfection. Thassophobia is intolerance of idleness. Gamophobia is intolerance of marriage/commitment. Gymnophobia is intolerance of nudity. Obesophobia is intolerance of obesity. As the examples show, there is a metaphorical conceptualisation of the root as an entity with physical extension. That is, in this metaphor an abstract concept is conceptualized as though it were a physical entity.

\section{Concluding remarks}

The present study has applied two cognitive concepts to the analysis of -phobia. One is polysemy which characterises lexical items as having multiple senses. The other is category which characterises the multiple senses as forming networks structured in prototype-periphery terms. The principles that relate the senses are generalisation, specification and metaphor. In terms of polysemy, a lexical item like -phobia constitutes a conceptual category of distinct but related senses. The senses can be judged as prototypical or peripheral. They are found to be related to one another. The relations 
between the senses are not arbitrary, but are rather principled. The prototypical sense is found to denote fear of a concrete entity. The less prototypical sense is found to denote hatred of a concrete entity. The peripheral sense is found to denote intolerance of an abstract entity. The semantic network of the suffix -phobia reflects, therefore, not only physical objects but also abstract notions. In doing so, the present study proves that a network mode of storing lexical items with multiple meanings is cognitively solid.

The study has found that the cognitive approach departs from both traditional and formal approaches to lexical meaning in the following ways:

1. Polysemy is considered an organising cognitive phenomenon, not a purely linguistic one. Linguistic meaning is dynamic. It is an emergent phenomenon. It results from the interaction between the meanings of the different elements of a lexical item. The same cognitive mechanisms structure linguistic as well as non-linguistic categories.

2. Lexical items form categories structured with respect to a prototype. The other members are related to it by convention rather than by generation. Thus, it is not lists of meanings but networks that characterise the relationships among the senses of polysemous items. The categories are open. They embrace new senses whenever new phenomena are encountered.

3. Categorisation is a mental process which shows how the multiple senses of a lexical item are stored in long-term memory. Categorisation is not a device for generating distinct meanings from the prototypical sense. As such, senses associated with lexical items are stored in the mental lexicon as distinct, yet related, semantic entities.

A graphical representation of the multiple senses of the suffix -phobia is offered in the figure below. Note that the solid arrow represents the prototypical sense, whereas the dashed arrows represent the semantic extensions.

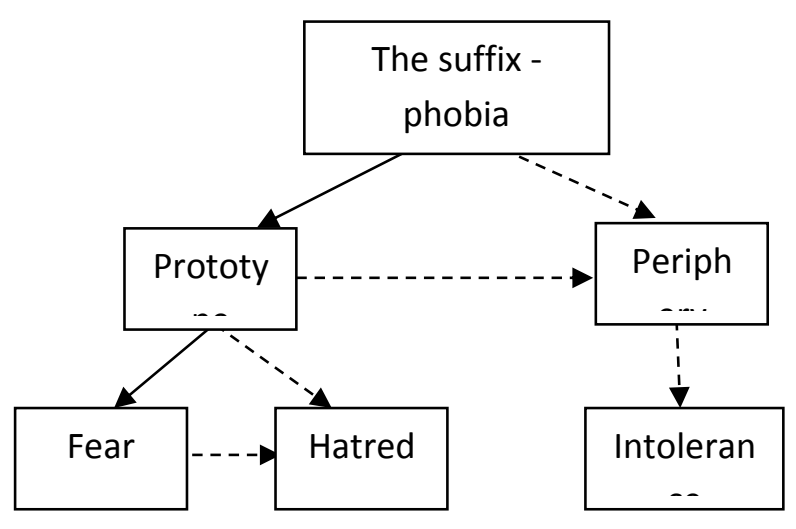

The semantic network of the suffix -phobia. 


\section{Notes}

1 For comprehensive coverage of the topic of polysemy, see Ravin and Leacock (2002), Cuyckens, et al. (2003), Cuyckens and Zawada (2001), Geeraerts (1988, 1994), and Nerlich, et al. (2003).

2 For full coverage of the topic of categorisation, see Rosch (1977, 1978), Lakoff (1987), Geeraerts (1988), Taylor (1989), and Evans (2003).

\section{References}

- Brugman, Claudia. 1988. The Story of over: Polysemy, Semantics, and the Structure of the Lexicon. New York: Garland.

- Brugman, Claudia, and George Lakoff. 1988. Cognitive topology and lexical networks. In Lexical Ambiguity Resolution: Perspectives from

- Psycholinguistics, Neuropsychology and Artificial Intelligence, edited by S. Small, G. Cottrell and M. Tannenhaus. San Mateo, California: Morgan Kaufman: 477-507.

- Cambridge Advanced Learner's Dictionary. 2013. Cambridge: Cambridge University Press.

- Cruse, Alan. 2006. A Glossary of Semantics and Pragmatics. Edinburgh: Edinburgh University Press.

- Cuyckens, Hubert and Britta Zawada (2001) Polysemy in Cognitive Linguistics.Amsterdam: John Benjamins.

- Cuyckens, Hubert, et al. 2003. Cognitive Approaches to Lexical Semantics. Berlin: Mouton de Gruyter.

- Evans, Vyvyan. 2003. The Structure of Time: Language, meaning and temporal cognition. Amsterdam: Benjamins.

- Evans, Vyvyan \& Melanie Green. 2006. Cognitive Linguistics: An Introduction. Edinburgh: Edinburgh University Press.

- Geeraerts, Dirk. 1988. "Cognitive Grammar and the History of Lexical Semantics". In Brygida Rudzka-Ostyn (ed.) Topics in Cognitive Linguistics: 647-677.

- Geeraerts, Dirk. 1994. Polysemy. In The Encyclopedia of Language and Linguistics. Oxford: Pergamon. 3227-3228.

- Hamawand, Zeki. 2009. The Semantics of English Negative Prefixes. London: Equinox.

- Hamawand, Zeki. 2016. Semantics: A Cognitive Account of Linguistic Meaning. Sheffield: Equinox.

- Katz, Jerrold. 1972. Semantic Theory. New York: Harper \& Row.

- Lakoff, George. 1987. Women, fire and dangerous things: What categories reveal about the mind. Chicago: University of Chicago Press. 
- Langacker, Ronald. W. 1987. Foundations of Cognitive Grammar, Vol. 1: Theoretical Prerequisites. Stanford: Stanford University Press.

- Langacker, Ronald. 1991. Foundations of Cognitive Grammar. Vol. 2: Descriptive Application. Stanford: Stanford University Press.

- Longman Dictionary of Contemporary English. 2003.

- Nerlich, Brigitte, et al. 2003. Polysemy: Flexible Patterns of Meaning in Mind and Language. Berlin: Mouton de Gruyter.

- Oxford Advanced Learner's Dictionary. 2005. Oxford: Oxford University Press.

- Oxford Dictionary of Synonyms and Antonyms. 2007. Oxford: Oxford University Press.

- Pustejovsky, James. 1995. The Generative Lexicon. Cambridge: MIT Press.

- Ravin, Yael \& Claudia Leacock. 2002. Polysemy: An Overview. Oxford: Oxford University Press.

- Rosch, Eleanor. 1977. "Human categorisation". In Neil Warren. (ed.) Studies in CrossCultural Psychology 1: 3-49.

- Rosch, Eleanor. 1978. "Principles of categorisation". In E. Rosch \& B. B. LIoyd (eds.) Cognition and Categorisation: 27-48.

- Ruhl, Charles. 1989. On Monosemy: A Study in Linguistic Semantics. Albany, New York: State University of New York Press.

- Taylor, John. 1989. Linguistic Categorisation. Prototypes in Linguistic Theory. Oxford: Clarendon Press.

- Tyler, Andrea., and Vyvyan Evans. 2003. The Semantics of English Prepositions. Cambridge: Cambridge University Press. 